Theologische Realenzyklopädie

Band XXXV 



\title{
Theologische Realenzyklopädie
}

\author{
In Gemeinschaft mit \\ Horst Balz - James K. Cameron \\ Christian Grethlein - Stuart G. Hall \\ Brian L. Hebblethwaite - Karl Hoheisel \\ Wolfgang Janke - Volker Leppin \\ Knut Schäferdiek · Gottfried Seebaß \\ Hermann Spieckermann · Günter Stemberger \\ Konrad Stock \\ herausgegeben von \\ Gerhard Müller
}

Band XXXV

Vernunft III - Wiederbringung aller

Walter de Gruyter - Berlin - New York 2003 
Lieferung 1/2 Vernunft III - Vorsehung I März 2003

Lieferung 3/4 Vorsehung I - Werke, Gute IV Juni 2003

Lieferung 5 Werke, Gute IV - Wiederbringung aller Oktober 2003

(0) Gedruckt auf säurefreiem Papier, das die US-ANSI-Norm über Haltbarkeit erfüllt.

ISBN 3-11-017781-1

Bibliografische Information Der Deutschen Bibliothek

Die Deutsche Bibliothek verzeichnet diese Publikation in der Deutschen Nationalbibliografie; detaillierte bibliografische Daten sind im Internet über http://dnb.ddb.de abrufbar

(C) Copyright 2003 by Walter de Gruyter GmbH \& Co. KG, D-10785 Berlin.

Dieses Werk einschließlich aller seiner Teile ist urheberrechtlich geschützt. Jede Verwertung außerhalb der engen Grenzen des Urheberrechtsgesetzes ist ohne Zustimmung des Verlages unzulässig und strafbar. Das gilt insbesondere für Vervielfältigungen, Ubersetzungen, Mikroverfilmungen und die Einspeicherung und Verarbeitung in elektronischen Systemen.

Printed in Germany

Satz und Druck: Tutte Druckerei GmbH, Salzweg-Passau

Buchbinderische Verarbeitung: Lüderitz \& Bauer, Berlin 